\title{
Reflexões sobre jornalismo literário e cotidiano
}

\author{
Notes on literary journalism and daily life
}

Apuntes sobre periodismo literario y vida cotidiana

Monica MARTINEZ ${ }^{1}$

\section{Resumo}

Este estudo teórico aponta a relação entre o campo dos Estudos de Jornalismo Literário e a cobertura jornalística sobre os acontecimentos diários. De natureza comum, ordinária, eles tendem a ser vistos como eventos banais, que não são percebidos pelas instituições jornalísticas como tendo potencial noticioso. Como referencial, emprega clássicos da área (Bak, Castro, Keeble, Lima, Passos e Sims, entre outros), destacando as contribuições de Kramer. À guisa de resultado, esta imersão no cotidiano dos entrevistados permite, de um lado, mergulhar de uma forma intimista nos aspectos e nas problemáticas mais subjetivas dos acontecimentos. Do outro, propicia uma conexão densa com as questões sociais, econômicas e históricas nas quais os entrevistados estão envolvidos.

Palavras-chave: Jornalismo Literário; História do Jornalismo Literário; Cotidiano; Pesquisa em Jornalismo.

\begin{abstract}
This theoretical study points out the relationship between the field of Literary Journalism Studies and journalistic coverage of daily events. Of common, ordinary nature, they tend to be seen as trivial events, which are not perceived by journalistic institutions as having news potential. As its main reference, it employs classic authors in the field (Bak, Castro, Keeble, Lima, Passos and Sims, among others), highlighting the contributions of Kramer. As a result, this immersion in the interviewees' daily life allows, on the one hand, to delve in an intimate way into the more subjective aspects and issues of the events. On the other hand, it provides a dense connection with the social, economic and historical issues in which the interviewees are involved.
\end{abstract}

\footnotetext{
${ }^{1}$ Docente do Programa de Pós-graduação em Comunicação e Cultura da Uniso/SP, onde é líder do Grupo de Pesquisa Jornalismo Literário e Narrativas de Transformação Pessoal e Social (JORLIT). É Bolsista de Produtividade em Pesquisa do CNPq - Nível 2. - E-mail - monica.martinez@prof.uniso.br ORCID oooo-0003-1518-8379.
} 
Keywords: Literary journalism; History of Literary Journalism; Routine events; Research in Journalism.

\section{Resumen}

Este estudio teórico señala la relación entre el campo de los Estudios de Periodismo Literario y la cobertura periodística de los hechos cotidianos. De naturaleza común y corriente, tienden a ser vistos como eventos triviales, que las instituciones periodísticas no perciben como potenciales informativos. Como principal referente, emplea a autores de lo campo (Bak, Castro, Keeble, Lima, Passos y Sims, entre otros), resaltando los aportes de Kramer. Como resultado, esta inmersión en la vida cotidiana de los entrevistados permite, por un lado, ahondar de manera íntima en los aspectos y cuestiones más subjetivas de los hechos. Por otro lado, proporciona una conexión densa con los temas sociales, económicos e históricos en los que están involucrados los entrevistados.

Palabras clave: periodismo literario; Historia del periodismo literario; Vida cotidiana; Investigación en periodismo.

Literary journalism begins with the reality of the world as we find it. O jornalismo literário começa com a realidade do mundo como a encontramos (tradução nossa).

Norman Sims

\section{Introdução}

Do ponto de vista acadêmico, no campo de estudos anglófonos, a pedra fundamental teórica dos Estudos de Jornalismo Literário costuma ser considerada o lançamento do livro The New Journalism, de 1973, do jornalista Tom Wolfe (19302018) (WOLFE, 2005; WOLFE; JOHNSON, 1973). Na obra, ao analisar o trabalho de mais de 20 jornalistas da época, Wolfe elencou quatro recursos que norteavam a produção do período:

Esse poder extraordinário se originava de quatro recursos apenas, descobriram eles. O básico era a construção cena a cena, contar a história passando de cena para cena e recorrendo o mínimo possível à mera narrativa histórica. Daí os feitos de reportagem às vezes extraordinários que os novos jornalistas empreendiam: para poder testemunhar de fato as cenas da vida das outras pessoas no momento em que ocorriam - registrando o diálogo completo, o que constituía o recurso número 2. Os escritores de revista, assim como os primeiros romancistas, aprenderam por tentativa e erro algo que desde então tem 
sido demonstrado em estudos acadêmicos: especificamente, que o diálogo realista envolve o leitor mais completamente e com mais eficiência do que qualquer outro recurso [...].

O terceiro recurso era o chamado "ponto de vista de terceira pessoa", a técnica de apresentar cada cena ao leitor por intermédio dos olhos de um personagem em particular, dando ao leitor a sensação de estar dentro da cabeça do personagem, experimentando a realidade emocional da cena como o personagem o experimenta. Os jornalistas muitas vezes usavam o ponto de vista da terceira pessoa - "eu estava lá" - da mesma forma que o usavam os autobiógrafos, memorialistas e romancistas. Isso, contudo, é muito limitador para o jornalista, uma vez que ele só pode levar o leitor para dentro da cabeça de um personagem - ele próprio -, um ponto de vista que muitas vezes se mostra irrelevante para a história e irritante para o leitor. Porém, como pode um jornalista, escrevendo não-ficção, penetrar acuradamente os pensamentos de outra pessoa?

A resposta mostrou-se deslumbrantemente simples: entreviste-o sobre seus sentimentos e emoções, junto com o resto. Foi isso que eu fiz n'O teste do ácido do refresco elétrico, o que John Sack fez em $M$ e o que Gay Talese fez em Honor thy father (Honra teu pai).

O quarto recurso sempre foi o menos entendido. Trata-se do registro dos gestos, hábitos, maneiras, costumes, estilos de mobília, roupas, decoração, maneiras de viajar, comer, manter a casa, modo de se comportar com os filhos, com os criados, com os superiores, com os inferiores, com os pares, além de vários ares, olhares, poses, estilos de andar e outros detalhes simbólicos do dia a dia que possam existir dentro de uma cena. Simbólicos de que? Simbólicos, em geral, do status de vida da pessoa, usando essa expressão no sentido amplo de todo o padrão de comportamento e posses por meio do qual a pessoa expressa sua posição no mundo ou o que ela pensa que é seu padrão ou o que gostaria que fosse. O registro desses detalhes não é mero bordado em prosa. Ele se coloca junto ao centro do poder do realismo, assim como qualquer outro recurso da literatura (MARTINEZ, 2016a, p. 175176; WOLFE, 2005, p. 53-55).

Além de sistematizar de forma pioneira os principais elementos de escrita, Wolfe chamou os praticantes da época de novos jornalistas - e no rastro o termo Novo Jornalismo acabou nomeando o movimento ou período do Jornalismo Literário dos anos 1960 e 1970. No Brasil, vários autores refletiram sobre o manifesto de Wolfe (CASTRO, 2010; LIMA, 2009; PASSOS; ORLANDINI, 2008). Poucos, como o estudioso britânico Richard Keeble, apontaram que a concentração dos estudos nas "técnicas individuais (que se mostrou tão influente no desenvolvimento do jornalismo literário no ensino superior) decisivamente segregou a consideração de elementos como ideologia e economia política, promovendo uma forma problemática de elitismo cultural” neste campo de estudos (KEEBLE, 2018a, 2018b). Poderíamos, ao raciocínio 
de Keeble, acrescentar a noção de cotidiano, que também poderia ser melhor aprofundada nos estudos.

No Brasil, esta observação de foco nas técnicas individuais pode ser observada em pesquisa realizada com 27 trabalhos apresentados no congresso anual da Sociedade Brasileira de Estudos Interdisciplinares (Intercom), no período de 2001 a 2007, em que 10 trabalhos consistiam em estudos de caso, isto é, tinham como intenção analisar um produto jornalístico (MARTINEZ, 2009a). A conclusão do estudo aponta uma hipótese que explicaria este fenômeno, ao sugerir "que o Jornalismo Literário pesquisado e provavelmente disseminado no ensino de Jornalismo brasileiro é o do século XIX / XX, quando a profissão jornalística estava em formatação e parte do material jornalístico era feita por escritores" (MARTINEZ, 2009a, p. 210). Esta constatação corrobora a proposta de Peruzzo (2018), que nota a predominância do nível descritivo das pesquisas científicas do campo da comunicação brasileiro:

\begin{abstract}
Enquanto abordagens de primeira ordem são descritivas das propriedades e elementos, as de segunda ordem são mais reflexivas e capazes de perceber as relações entre os observáveis e de cruzar teorias. Aquelas abordagens que miram os processos e desenvolvem um nível de interpretação ainda mais elevado, ao serem capazes de gerar conceitos são as de terceira ordem. As de quarta ordem são ainda mais avançadas pois desenvolvem teorias e partem da epistemologia para a interpretação, análise e explicação dos problemas teóricos e metodológicos (PERUZZO, 2018, p. 34).
\end{abstract}

Fica evidente, portanto, que por estarem focados na análise das técnicas individuais e por serem em sua maioria descritivos, as pesquisas em Jornalismo Literário poderiam aprofundar outros elementos importantes, como a relação com o cotidiano. O que é a seu modo um paradoxo, pois desde seu princípio a questão foi essencial na reflexão deste campo de estudos, uma vez que ela era parte fundamental do fazer dos jornalistas literários.

No Brasil, esta mirada sobre cotidiano está presente em jornalistas pioneiroscomo Euclides da Cunha (CUNHA, 1944, 2016) e João do Rio (RIO, 1976, 2015, 2017), refletindo-se nos estudos sobre eles feitos. Destaca-se que Cunha e Rio encontram-se entre os poucos autores nacionais a ter obras traduzidas em inglês, o que permite que sua produção transcenda o mundo lusófono. Essa falta de tradução contribui para que obras em inglês liderem as referências no campo de estudos no mundo. Um bom exemplo é o livro A Sangue Frio, o mais empregado no ensino da 
disciplina em nível internacional, segundo pesquisa internacional feita pelos estudiosos John Hanc, do New York Institute of Technology, EUA e Mitzi Lews, Midwestern State University, EUA (LEWIS; HANC, 2018, p. 780).

Nesta obra clássica dos estudos do Jornalismo Literário, o autor, Truman Capote, fez uma notável imersão a posteriori do desenrolar dos fatos, incluindo o dia a dia dos assassinos, Perry Smith e Dick Hikcock, para compor o relato. Do outro lado, o autor apresenta o registro minucioso do cotidiano da família Clutter, na pacata Holcomb, Kansas (EUA), em 1959. O livro foi lançado em 1965 (CAPOTE, 1980), depois de ter sido publicado como uma reportagem seriada (GAPY, 2018) em quatro partes na revista The New Yorker. Assim, a reconstrução do massacre do fazendeiro Herbert Clutter, de sua esposa Bonnie e dos filhos Nancy e Kenyon - exemplo de uma família estadunidense padrão dos anos 1950, unida, religiosa, devotada à comunidade -, consegue lançar luzes, por meio do registro do cotidiano, de um importante momento histórico de um país e de um mundo que se encontrava em transição.

Ainda que focado nas técnicas individuais, o boom do Novo Jornalismo despertou a atenção de acadêmicos estadunidenses nos anos 1980 que começaram a observar, analisar e publicar sobre o fenômeno do Jornalismo Literário daquele período. Foi o caso de Norman Sims (SIMS, 1984) e Thomas B. Connery (CONNERY, 1992), entre outros, aos quais se seguiram Nancy Roberts (EMERY; EMERY; ROBERTS, 1999) e John J. Pauly (PAULY, 2011).

O Brasil seguiu de perto a tendência de sistematização do campo por meio de pesquisadores como Edvaldo Pereira Lima, docente aposentado da Escola de Comunicações e Artes da Universidade de São Paulo, considerado o pioneiro nestes estudos por meio de sua tese de doutorado, publicada pela Unicamp em 1993 (LIMA, 1993), que seria lançada mais tarde numa edição revista e ampliada pela Editora Manole (LIMA, 2009). Outros pesquisadores buscaram investigar marcos do Jornalismo Literário brasileiro, como a revista Realidade (FARO, 1999) ou, mais recentemente, a piauí (BRUCK; ANTUNES, 2017), além de escritores jornalistas do país (COSTA, 2005) ou mesmo teorizar o Jornalismo Literário (PENA, 2006), entre outros.

A verdade é que não há consenso sobre o termo Jornalismo Literário (CASTRO, 2010). Aliás, não há sequer entre os estudiosos qualquer pretensão de que haja um denominador terminológico comum (HARTSOCK, 2000). Ainda assim, o principal espaço de discussão de estudiosos da modalidade no mundo, a IAJLS (International 
Association for Literary Journalism Studies), adotou o termo em 2006, entendendo que se trata de jornalismo como literatura e não sobre literatura, o que ajuda bastante a explicar a natureza da preocupação central dos estudiosos.

Seja no Brasil, seja nos demais países, sobretudo Estados Unidos, França, Canadá e Portugal, o Jornalismo Literário recebe variadas denominações, como "Jornalismo Narrativo, Literatura da Realidade, Literatura Criativa de Não Ficção" (LIMA, 2016b), entre outros. O termo Literatura da Realidade remete a um dos expoentes da prática, o jornalista estadunidense Gay Talese, que entende que o jornalista pode empregar recursos literários para reportar melhor a realidade. Já Literatura Criativa de Não Ficção é uma tradução do espanhol Periodismo informativo de Creación, que remete à Fundación Gabriel García Márquez (1927-2014) para El Nuevo Periodismo Iberoamericano.

No Brasil, a escola de São Bernardo, por exemplo, caracteriza a modalidade como integrante do gênero diversional (MELO; ASSIS, 2010), não no sentido de entretenimento, mas de diverso (COSTA, 2015), por estar mais ligada ao estudo do formato do que propriamente do conteúdo ou dos processos produtivos. Igualmente relacionado à forma, há termos internacionais recentes com alguns estudos no Brasil, como Long Form Journalism (LONGHI; WINQUES, 2015). Há, entretanto, especialistas que acreditam que a prática esteja mais relacionada à questão estética e à experiência, como defendida no mais recente livro do estudioso estadunidense John C. Hartsock (HARTSOCK, 2016).

Quando se emprega o termo Jornalismo Narrativo, por exemplo, em geral remete-se ao grupo ligado à Fundação Nieman, o braço jornalístico da Universidade Harvard, nos Estados Unidos, particularmente ao início dos anos 2000, período em que esta fundação foi dirigida pelo docente Mark Kramer ((2001-2007). Não é raro, também, pesquisadores e praticantes proporem seu próprio termo ou empregar terminologias específicas, como Novo Jornalismo, como se fossem descoladas desse movimento. Entendemos que este termo descreva uma fase do Jornalismo Literário de grande repercussão midiática, ligada aos anos 1960-1970, em particular nos Estados Unidos por meio de nomes como Truman Capote (1924-1984), Norman Mailer (19232007), Gay Talese e Tom Wolfe, entre outros. Há também controvérsias entre os estudiosos se outras derivações, como o Jornalismo Gonzo (RITTER, 2015), fariam parte do escopo do Jornalismo Literário, dadas às condições de produção específicas desta modalidade. 
Iniciou-se, desde o princípio, uma tentativa de estabelecer a taxonomia do então considerado gênero híbrido, que era jornalístico, porque baseado em fatos, mas que parecia ir além do jornalismo, porque tinha elementos similares aos dos romances. Como é conhecido, a mistura de fatos e ficção de obras famosas da época, como a citada A Sangue Frio, acalorava ainda mais o debate na época. Contudo, é importante lembrar que, apesar de ter se autopromovido como o criador do romance de não ficção, Capote não foi o idealizador de um novo gênero como ele se autoproclamava, uma vez que ele tinha conhecimento de outras iniciativas precursoras, das quais nos limitamos a citar aqui o livro-reportagem Picture / Fïlme, de Lilian Ross (ROSS, 2005). Lançado em 1952, depois de também ter sido publicado como reportagem seriada na revista The New Yorker naquele ano, a obra tem como fio condutor um acontecimento comum: a autora cobrindo por um ano o dia a dia da produção do filme de John Hustons, de 1951, The Red Badge of Courage. Por meio do acesso que teve, Ross cria o que é uma obraprima sobre o cinema hollywoodiano.

Do ponto de vista acadêmico, portanto, as pesquisas do campo dos Estudos do Jornalismo Literário nas comunidades lusófonas e anglófonas começaram a ser feitas de forma mais sistemática nos anos 1990. E uma das obras em que a questão do cotidiano está mais em destaque é a publicada em 1995 pelos estudiosos Norman Sims e Mark Kramer. Nela, destaca-se a introdução escrita por Kramer, Breakable Rules for Literary Journalists, que pode ser traduzida como Regras Quebráveis para Jornalistas Literários (KRAMER, 1995a).

É a partir desta obra que argumentaremos que uma parte consistente da produção em Jornalismo Literário e, consequentemente das reflexões do campo, se debruça sobre o que Kramer chama de acontecimentos rotineiros, isto é, cotidianos. Para embasar nosso argumento, usaremos a produção de três livros reportagem do próprio Kramer.

\section{O mundo extraordinário das pessoas e dos acontecimentos comuns}

Há estudos prévios que registram a importância do pensamento de Kramer no campo dos estudos de Jornalismo Literário. Eles abordam: 1) A definição famosa de que o Jornalismo Literário teria sido mais conhecido como uma forma "you-know-itwhen-you-see-it" ("você sabe quando a vê", em tradução nossa) (MARTINEZ, 2017, p. 65). 2) As oito características por ele apontadas que identificariam os textos (MARTINEZ, 2009b, p. 80; PASSOS; ORLANDINI, 2008, p. 85). 3) A ênfase que daria 
à prática e às reflexões teóricas por meio dos encontros realizados na Boston University desde o início da década de 1990 e, a partir de 2001, na Nieman Foundation, o braço jornalístico da Harvard University (LIMA, 2016a, s/p). 4) A contribuição na organização de livros, como Telling true stories, editado em parceria com endy Call, Writing for Story (LIMA, 2013, p. 69). 5) O senso de deselfed defendido por ele, isto é, de que o jornalista, em sua ânsia de se distanciar das notícias para tratála de maneira supostamente objetiva, estaria produzindo, de forma mecânica, peças desumanas (COUTINHO, 2017, § 2). 6) A produção de Kramer como jornalista (SIMÃO, 2018).

Ressalta-se que, antes de escrever esta introdução, Kramer tinha vasta experiência como jornalista literário, trabalhando para vários diários e revistas, como a NYTimes Sunday Magazine, National Geographic e The Atlantic Monthly, entre outros. Seus livros - nenhum deles ainda traduzido no Brasil - incluem imersões no cotidiano de segmentos sociais diferentes dos Estados Unidos.

Destacamos três obras do autor aqui relativas ao tema que estamos abordando. A primeira é Invasive procedures (Procedimentos invasivos, em tradução nossa), com primeira edição lançada em 1983 (KRAMER, 1983). Para escrever este livroreportagem, Kramer acompanhou por um ano a vida de dois cirurgiões de Nova Iorque. Por meio da imersão no cotidiano dos profissionais, o jornalista conseguiu refletir sobre o universo dos cirurgiões estadunidenses nos anos 1980. Uma resenha publicada no New York Times resgata a ideia do projeto: "quinze anos atrás [de 1983], aos 23 anos, Mark Kramer (...) sofreu um procedimento cirúrgico para remover um caroço do quadril. Tratava-se de uma operação de rotina, o tumor era benigno, mas a experiência parece ter exercido sobre ele um efeito não muito diferente daquele que o raio teve sobre Saulo de Tarso (MCGINNISS, 1983, tradução nossa) ${ }^{2}$. O resultado é que, segundo McGinniss, Kramer ficou tão impressionado pela experiência imersiva no cotidiano dos profissionais ao escrever a obra que, ainda que brevemente, chegou a se sentir integrado à equipe. Sabemos também pela resenha que, em reação à cirurgia, Kramer

\footnotetext{
${ }^{2}$ No original: "FIFTEEN years ago, at the age of 23, Mark Kramer, who is now a member of the Smith College faculty, underwent surgery for the removal of a lump on his hip. The operation was routine, the lump benign, but the experience seems to have had upon him an effect not unlike that which the bolt of lightning had upon Saul of Tarsus (MCGINNISS, 1983).
} 
deixou seu emprego e se mudou da cidade de Nova Iorque para uma fazenda da Nova Inglaterra (MCGINNISS, 1983, tradução nossa)3.

O segundo de seus livros, não por acaso é Three farms: making milk, meat and money in the American soil (KRAMER, 1986), em tradução livre Três fazendas: produzindo leite, carne e dinheiro com o solo americano. Na obra, Kramer mergulha no perfil de três fazendeiros - um criador de vacas leiteiras de Massachusetts, um agricultor de Iowa dedicado ao cultivo de milho e à criação de suínos e um produtor da Califórnia - para documentar a situação dos pequenos agricultores americanos e seu modo de vida que, no final dos anos 1980, estava em vias de desaparecer. Mark Wilde faz uma observação interessante ao dizer que na época do lançamento do livro a crise no segmento de agribusiness estadunidense estava gradualmente desaparecendo das capas das revistas como Time e Newsweek, mas que o acompanhamento do cotidiano do setor feito por Kramer permitia entender o processo de transformação agrária nele sofrido (WILDE, 1988). O que permite estabelecer aqui um paralelo com outra obra clássica do Jornalismo Literário e da reportagem fotográfica, Elogiemos os homens ilustres, que registra por meio do cotidiano lavradores pobres do Alabama, em 1936, os efeitos da Grande Depressão de 1929 (AGEE; EVANS, 2009).

Uma terceira obra de Kramer, lançada em 1995, também ilustra bem o conceito de registros do cotidiano como representativo de movimentos e momentos históricos importantes. Trata-se de Travels with a hungry bear: a journey to the Russian heartland (KRAMER, 1995b), em tradução livre Viagens com um urso faminto: uma jornada para o coração da Rússia. Para uma série de reportagens para a New York Times Magazine, Kramer decide descobrir o motivo que uma nação do tamanho da então União Soviética sofria com escassez e racionamento. De 1987 a 1993, em viagens sucessivas, o autor revisitou muitos lugares e personagens, de oficiais do ministério a operadores de trator. Na obra, por meio destes relatos do cotidiano, o jornalista revela a alma de um povo que atravessava um momento histórico: o impacto da reestruturação econômica que o então presidente Mikhail Gorbachev lançava, que ficou mundialmente conhecido como perestroika (1985-1991).

Esta breve análise sobre as três obras é importante para entendermos a reflexão de Kramer como um marco dos estudos do Jornalismo Literário em nível

\footnotetext{
3 DN original: "It was, he tells us, in reaction to the surgery that he left his job and moved from New York City to "a farm in the New England hills" (MCGINNISS, 1983).
} 
internacional, uma vez que ela integra o processo de sistematização do campo a partir da perspectiva estadunidense (KRAMER, 1995a). Assim, ao escrever a introdução do livro de 1995, Kramer atribui tamanha importância ao relado do cotidiano como uma ponte para a compreensão, por meio de personagens e situações comuns, de momentos históricos. Embora ele não se detenha a discutir esta relação, suas reflexões tangenciam os métodos empregados pela área da história, notadamente a história oral (ALBERTI, 2005; MARTINEZ, 2016b; MEIHY; RIBEIRO, 2011; PERAZZO, 2015; THOMPSON, 2002). No Brasil, esta relação com o cotidiano ficaria mais clara do ponto de vista produtivo e também de reflexão teórica, a partir de autores como Eliane Brum (DA SILVA; MAROCCO, 2018; LIMA; MARTINEZ, 2014; MARTINEZ, 2014).

Desta forma, das oito regras do Jornalismo Literário que elenca, Kramer dedica uma especificamente para abordar a importância da observação dos acontecimentos costumeiros, recorrentes, regulares (ver SODRÉ, 2009). Como diz o título da introdução, são regras quebráveis, rompíveis se necessário, mas ainda assim orientações importantes da prática. Destacamos aqui a terceira, diretamente relacionada à questão do registro do cotidiano, com a qual vamos dialogar a seguir:

\section{3) Jornalistas literários escrevem na maioria das vezes sobre acontecimentos rotineiros}

A ecologia do acesso conveniente leva jornalistas literários a eventos rotineiros, não a eventos extraordinários. A necessidade de se obter acesso franco, de longo prazo, tem obrigado os escritores a procurar material em locais que podem ser visitados e a evitar, apesar dos desejos em contrário, lugares que não podem. O nível de acesso necessário é tão alto que determinou amplamente a direção dos esforços dos jornalistas literários (KRAMER, 1995a, p. 27, tradução nossa) 4 .

Nesta orientação, Kramer afirma que acontecimentos comuns são a principal matéria-prima das peças em Jornalismo Literário, que precisa, em geral, de acesso aberto e de longo prazo - como a imersão de um ano na vida dos cirurgiões - para contar seu modo de vida. Por outro lado, este relacionamento de longo prazo também suscita uma questão candente sobre a relação ética do/a repórter com a fonte:

\footnotetext{
4 No original: "The ecology of convenient access impels literary journalists toward routine events, not extraordinary ones. The need to gain long-term, frank access has forced writers to seek material in places that can be visited, and to avoid, in spite of longings to the contrary, places that can't. The level of access required is so high that it has largely determined the direction of literary journalists' efforts" (KRAMER, 1995a, p. 27).
} 
O objetivo durante a "reportagem" ou o "trabalho de campo" não é o de se sociabilizar como se fosse um interno, como um funcionário que tem uma função numa empresa. Na verdade, o objetivo é saber o que esses internos pensam, a fim de conhecer suas experiências e perspectivas e entender como é a rotina deles. De início, quando passei tempos com cirurgiões, sangue era algo que me assustava - um comportamento anticirurgião, diga-se. Depois de um ano presenciando toda aquela confusão organizada, meu olhar havia mudado. Pela própria reação do médico, eu sabia quando um sangramento era algo normal, e passei a reconhecer os raros momentos em que isso alarmava os médicos. Minha reação de principiante não era relevante para o mundo dos cirurgiões; e minhas reações posteriores me ajudaram a compreender os pontos de vista deles (KRAMER, 1995a, p. 27, tradução nossa) 5 .

Kramer deixa bem claro aqui o processo sugerido para que um jornalista literário faça imersão no campo para observá-lo, sem assumir, no entanto, uma posição de julgamento. Caso contrário, sua visão poderia ficar comprometida, uma vez que cristalizada num determinado foco experienciado pelo indivíduo ou grupo de indivíduos que se quer relatar. O risco maior, talvez, não seria o de perder uma dada neutralidade - o que se sabe ser ilusório -, mas o de se fixar numa das percepções possíveis de um assunto.

Talvez nenhum autor tenha exposto - e se exposto - de forma tão profunda e literária sobre as consequências do contato prolongado com uma fonte como Joseph Mitchell em O Segredo de Joe Gould (MITCHELL, 2003), onde o sem-teto que ele acompanhou por mais de três anos para escrever um perfil passa a visitar a redação após a publicação para pedir pequenas colaborações financeiras para poder ajudar na sua sobrevivência.

O fato de o corpo principal do trabalho de um jornalista literário não consistir de eventos extraordinários, mas ordinários, não o diminui, nem o torna menos importante ou interessante. Ao contrário. Ajuda a lançar uma perspectiva humanizada, diferenciada, em relação à cobertura noticiosa. E acaba sendo uma extensão natural das grandes coberturas, quando não raro após as publicações das primeiras notícias

\footnotetext{
5 No original: "The goal during "reporting" or "fieldwork" is not to become socialized as an insider, as an intern at a firm might en route to a job. It is to know what insiders think about, to comprehend subjects' experiences and perspectives and understand what is routine to them. Insiders who eventually read a literary journalist' account should find it accurate and relevant, but not from an inside perspective. At first, when I spent time with surgeons, blood alarmed me - an unsurgeonlike attitude. By the end of a year witnessing controlled mayhem, my attention had shifted. I knew when the surgeon found bleeding routine, and recognized the rare moments when it alarmed him. My rookie reaction wasn't relevant to the surgeon's world; my later reaction served me better in comprehending his perspective" (KRAMER, 1995a, p. 27).
} 
ocorre o devido aprofundamento do impacto do acontecimento na vida do indivíduo e das comunidades, em geral por meio dos perfis humanizados (VILAS-BOAS, 2014). Como Kramer diz:

Rotina não quer dizer monotonia. A vida de quase todo mundo, descoberta em sua profundidade e com um olhar compassivo, é interessante. Alguns temas muito corriqueiros, no entanto, ainda não foram enfrentados, e são vistos como inacessíveis salvo pelos envolvidos (KRAMER, 1995a, p. 27, tradução nossa) ${ }^{6}$.

Num certo sentido, esta introdução do estudioso se adiantou no tempo. Feita há um quarto de século, num mundo pré-internet, ela não contou com a bem-vinda pluralidade de vozes que se ergueriam graças ao avanço tecnológico. Ainda assim, esta abertura de canais propiciada pelos ambientes digitais não dispensam o trabalho árduo do/a jornalista literário/a, uma vez que este/a exerce a função de relatar um dado cotidiano de forma aprofundada. Para obter esta visão ampla, em geral há um primeiro movimento de mapeamento e pesquisa seguidos de imersão. A seguir, ocorre um necessário movimento reflexivo que, para ser efetivo, pede um dado distanciamento no tempo e no espaço para que o material colhido daquela dada realidade possa ser visto em seu contexto maior, seja familiar, comunitário, social ou, numa perspectiva mais ampla, global.

Como qualquer método, esta abordagem tem seus limites, que o autor já apontava em 1995:

Estranhamente, o aspecto jurídico é uma limitação decisiva. Com a encomenda de uma revista nacional em mãos, uma vez fui até um advogado conhecido por defender efetivamente vários suspeitos de assassinato. Ele se sentiu tentado pela ideia de um artigo sobre seu trabalho cotidiano. Adiantei-lhe o acesso que eu precisava - incluindo a entrada nas suas reuniões com e sobre os clientes. $\mathrm{O}$ advogado acabou desistindo. Eu estaria quebrando a relação advogado/ cliente, ele me explicou, e eu poderia ser desafiado e talvez até intimado para depor sobre o eu que haveria ouvido. E seus clientes poderiam então processá-lo por má-conduta profissional (KRAMER, 1995a, p. 27, tradução nossa) 7 .

\footnotetext{
${ }^{6}$ No original: “Routine doesn't mean humdrum. Most anyone's life, discovered in depth and from a compassionate perspective, is interesting. Some very routine subjects, however, haven't been breached, and seem unbreachable except by insiders" (KRAMER, 1995a, p. 27).

7 No original: "Oddly, one major constraint is legal. Commission from a national magazine in hand, I once approached an attorney well known for effectively defending many suspected murderers. He was tempted by the prospect of an article about his daily work. I sketched out the access I'd need - including entrée to his office discussions with and about a current client. The attorney backed away. I'd be out beyond the umbrella of attorney-client privilege, he said, and could be challenged, and perhaps subpoenaed, for questioning on what I'd heard. His client could then sue him for malpractice" (KRAMER, 1995a, p. 27).
} 
Há outros limites que não foram mencionados por Kramer, mas que são relacionados à confidencialidade que ocorre em algumas atividades que envolvem uma prática dialógica, no qual o/a paciente pode expor determinadas questões tão secretas que ele/ela não o faria não fosse a segurança de estar se abrindo num campo seguro. É o caso das sessões de análise, no qual o setting, isto é, o espaço onde ocorre a sessão, é entendido como um vaso sagrado, no qual os conteúdos ali revelados não sairão daquele recinto. Salvo em situações extremas, que sejam explicitamente imorais e/ou ilegais, como por exemplo casos de abuso ou violência contra crianças ${ }^{8}$. Mas Kramer observa outros limites relativos ao acesso:

O acesso aos altos postos de grandes empresas durante uma negociação importante também se tem mostrado quase impossível, principalmente porque os envolvidos entendem que a permanência de um jornalista pode exceder o grau de responsabilidade fiduciária prudente e influenciar no resultado da negociação. Além disso, os empresários trabalham repetidamente em um círculo de associados, e quem deixar entrar um escritor desvinculado da perspectiva de vantagem mútua neste círculo pode ser visto como um rompedor desta confiança. De vez em quando, autores conseguem quebrar essa barreira. Algumas informações privadas já foram escritas por participantes da negociação. E reconstruções literárias "post-factum" às vezes recriam os dramas de negociações complexas (KRAMER, 1995a, p. 27-28, tradução nossa) 9 .

Esta possibilidade de cobertura a posteriori de certos acontecimentos que podem ser entendidos como relativos à cotidianidade abre um campo interessante, uma vez que nestas coberturas aprofundadas não há necessidade alguma de se recorrer a imediatismos, como na briga atual dos portais de notícia em lançar o primeiro link para alavancar os page views. Ao contrário. Como elabora Kramer:

\footnotetext{
8 Os artigos 13 e 245 do Estatuto da Criança e do Adolescente e, no caso da cidade de São Paulo, a Portaria $\mathrm{n}^{\circ}$ 2639/03 da SMS, informam que o profissional tem o dever ético e legal de comunicar aos órgãos competentes as suspeitas de violência.

9 No original: "Uncontaminated access to top levels of big business during a major deal has also proved nearly beyond reach, mostly because corporate sources perceive that allowing a journalist to roam might exceed prudent fiduciary responsibility, and might subject them to suit. Also, businesspeople work repeatedly within a circle of associates, and whoever let in a writer unbound by the circle's prospect of mutual advantage could be seen as breaking trust. Writers occasionally do make it through these barriers. A few kiss-and-tell versions of business deals have also been written by former players. And writerly post-factum reconstructions sometimes re-create dramas of complex deals" (KRAMER, 1995a, p. 27-28).
} 
As narrativas sobre crimes também reconstroem eventos "postfactum”. Assassinos costumam não colaborar com autores. Mas casos criminais subsequentemente abrem acesso para os mais secretos lugares a partir do momento em que o ato é revelado. Suspeitos de serem culpados por buscar liberdade, variedade ou perdão, parentes vingativos e registros bem feitos do tribunal têm levado escritores a mundos internos ocultos - depois do fato (KRAMER, 1995a, p. 28, tradução nossa) ${ }^{10}$.

Isso porque o tempo do jornalista literário é outro. Ele em tese é mais elástico em relação aos repórteres que se dedicam a produzir as primeiras versões da notícia, como Melo já conceituava os gêneros há meio quarto de século (MELO, 1994). Não há pressa em chegar, mas sim a preocupação em realizar coberturas diversas, complexas, humanas, temperadas por referenciais simbólicos que pedem que os fatos sejam cozidos no tempo lento da escuta (JÚNIOR, 2005; MARTINEZ, 2010; ZIELINSKI, 2006) e da reflexão para serem relatados. Até porque alguns envolvidos precisarão elaborar em si mesmos o que viveram antes de contar as narrativas com outro nível de densidade que não o do tempo presente:

\begin{abstract}
Autores de não ficção estão fadados a chegar mais tarde. Algo que um jornalista literário pode fazer apenas em primeira pessoa, em retrospectiva, depois que o acaso o tenha levado à boa ou má sorte, é escrever sobre alguém prestes a ser pego, a escorregar numa casca de banana ou a encontrar um pote de ouro. De vez em quando, algo desfavorável acontece com um escritor, e os leitores podem acabar presenteados com a desgraça deste. Vem-me à mente "The Incident of Naples", de Francis Steegmuller, publicado na revista The New Yorker em 1986. Steegmuller descreve-se sendo roubado e ferido durante um feriado. Talvez seja para empurrar este limite que escritores escolhem se aventurar - navegando em mares revoltos e vivendo para contar, caçando nas savanas da África para testar os limites. Antes do desastre que acabou com a vida de Christa MacAuliff e os astronautas da Challenger, a Nasa havia aberto inscrições para escritores interessados em viajar ao espaço. Entre os interessados estava Tracy Kidder, que passou a escrever sobre envelhecimento (KRAMER, 1995a, p. 28, tradução nossa) ${ }^{11}$.
\end{abstract}

\footnotetext{
${ }^{10}$ No original: "A cousin, true-crime reporting, also reconstructs events post-factum. Murderers usually try not to do their work in front of writers. But criminal cases subsequently open access to the most secret places, starting the moment the deed is revealed. Cooperative culprits looking for redemption, variety, or forgiveness; vengeful family members; and elaborate court records have taken writers far into hidden inner worlds - after the fact" (KRAMER, 1995a, p. 28).

${ }^{11}$ No original: "Nonfiction writers are fated to arrive late. Something that a literary journalist can only do in the first person, with hindsight, after chance has subjected him to bad or good fortune, is to write about a person about to be mugged, slip on a banana peel, or find a pot of gold. Once in a while, something untoward happens to a writer, and readers may profit from the author's misfortune - Francis Steegmuller's "The Incident at Naples" (which ran in The New Yorker in 1986) comes to mind. Steegmuller describes being robbed and injured while on holiday. Perhaps it is to push this limit that writers go adventuring - sailing into nasty seas and living to tell, hunting in the green hills of Africa and
} 
Entre os especialistas do campo um dos poucos consensos é o de que o Jornalista Literário tem em sua bagagem as ferramentas necessárias para processar os eventos do dia a dia e depurá-los de forma a extrair a essência deles, desvendando conexões invisíveis, sentidos ocultos, paradoxos inerentes.

\section{Reflexões finais}

Principiamos este estudo com o marco teórico anglófono do campo de estudos de Jornalismo Literário, proposto por Tom Wolfe em 1973, que influencia a tendência de as pesquisas se concentrarem nas técnicas individuais dos jornalistas literários até porque uma parte significativa dos estudiosos do campo estarem ligados a programas de literatura. Neste contexto, propomos a discussão aprofundada do manifesto de oito características textuais proposto por Kramer (1995a), que marca, por assim dizer, uma segunda onda de estudos do campo. Destas características, nos debruçamos sobre a terceira, que versa sobre o fato de que os jornalistas literários escreverem na maioria das vezes sobre acontecimentos rotineiros.

Mais do que uma estratégia, esta abordagem atende uma necessidade de acesso, como diz Kramer, uma vez que reportagens de fôlego em geral pedem acompanhamento de longo prazo. O que faz com que os jornalistas desta modalidade deem preferência a indivíduos que desejam colaborar com a reportagem.

Esta imersão no cotidiano dos entrevistados, que vimos aqui por meio da discussão de três livros publicados por Kramer, permite ilações mais amplas. É o caso das conexões sócio-históricas de clássicos do Jornalismo Literário como Elogiemos os homens ilustres, que registra por meio do cotidiano de lavradores pobres do Alabama, em 1936, os efeitos da Grande Depressão de 1929.

Como Norman Sims descreve em seu artigo no primeiro número da revista científica Literary Journalism Studies, este acompanhamento contínuo permite a imersão não somente no espaço e no tempo, mas também nos aspectos psicológicos, isto é, cognitivo, emocional e comportamental dos indivíduos, que consiste numa das chaves desta proposta narrativa:

bagging the limit in close calls. Before disaster destroyed the lives of Christa MacAuliff and the Challenger astronauts, NASA had signed up writers wishing to go space traveling. Among the applicants was Tracy Kidder, who has gone on instead to write about aging” (KRAMER, 1995a, p. 28). 
Em 1974, o estudioso James W. Carey pediu uma história cultural sistemática do jornalismo. Algo semelhante poderia ser proposto hoje para estudos de jornalismo literário. "A história cultural”, disse Carey, "não se preocupa apenas com eventos, mas com o pensamento dentro deles" - o "estudo da consciência no passado". Há uma importância para César atravessar o Rubicão, ele disse, mas estaríamos melhor servidos reconstruindo o que César sentiu ao atravessar o Rubicão - "a constelação particular de atitudes, emoções, motivos e expectativas que foram experimentadas naquele ato". Ele pediu que a comunidade acadêmica fosse além de um progresso jornalístico percebido em direção à precisão factual e à liberdade de imprensa e recuperasse o significado do jornalismo em seu próprio tempo (SIMS, 2009, p. 7, tradução nossa) ${ }^{12}$

Neste sentido, como dizia o antigo slogan da revista People, se trataria de relatar acontecimentos extraordinários de pessoas comuns e acontecimentos comuns de pessoas extraordinárias. Desta forma, o fato de o corpo principal do trabalho de um jornalista literário não consistir de eventos extraordinários, mas ordinários, não o diminui, nem o torna menos importante ou interessante. Ao contrário. Como defende Heller (2008), ajudaria a lançar uma perspectiva aprofundada em relação às estruturas da vida cotidiana nas quais estão inseridos seres humanos e suas coberturas noticiosas.

\section{Referências}

AGEE, J.; EVANS, W. Elogiemos os homens ilustres. 1. ed. São Paulo: Companhia das Letras, 2009.

AGUIAR, L. A. DE. O jornalismo investigativo e seus critérios de noticiabilidade: notas introdutórias. Revista Alceu, v. 7, n. 13, p. 73-84, 2006.

ALBERTI, V. Manual de História Oral. 3. ed. Rio de Janeiro: FGV, 2005.

BAITELlO JÚNIOR, N. A cultura do ouvir. In: A era da iconofagia: ensaios de comunicação e cultura. São Paulo: Hacker, 2005. p. 98-109.

\footnotetext{
${ }^{12}$ No original: "In 1974, the scholar James W. Carey called for a systematic cultural history of journalism. Something similar could be proposed today for literary journalism studies. "Cultural history," Carey said, "is not concerned merely with events but with the thought within them" - the "study of consciousness in the past." There's a significance to Caesar crossing the Rubicon, he said, but we would be well served by reconstructing what Caesar felt as he crossed the Rubicon-"the particular constellation of attitudes, emotions, motive and expectations that were experienced in that act." $\mathrm{He}$ called for historical scholarship that could move beyond a perceived journalistic progress toward factual accuracy and press freedom, and instead recapture the meaning of journalism in its own time" (SIMS, 2009, p. 7).
} 
BRUCK, M. S.; ANTUNES, R. Jornadas e heróis nos perfis da Revista Piauí: um estudo sobre gestos biográficos no Jornalismo. Revista Contracampo, v. 36, n. 3, dez/2017 mar./2018.

CAPOTE, T. A sangue frio: o relato frio de um assassinato múltiplo e suas complicações. São Paulo: Abril Cultural, 1980. CASTRO, G. DE. Jornalismo literário: uma introdução. Brasília: Casa das Musas, 2010.

CONNERY, T. B. A sourcebook of American literary journalism: representative writers in an emerging genre. New York: Greenwood, 1992.

COSTA, C. Pena de aluguel: escritores jornalistas no Brasil - 1904-2004. São Paulo: Companhia das Letras, 2005.

COSTA, L. A. DA. Gêneros jornalísticos. In: MELO, J. M. DE; ASSIS, F. de. Gêneros jornalísticos no Brasil. São Bernardo do Campo: Umesp, 2015. p. 43-83.

COUTINHO, M. J. DE C. Desafios para a historiografia do jornalismo literário português. Comunicação pública, v. 12, n. 22, 2017.

CUNHA, E. DA. Rebellion in the Backlands. Chicago: University of Chicago Press, 1944.

CUNHA, E. DA. Os sertões. Edição especial. São Paulo: Martin Claret, 2016.

DA SILVA, M. V.; MAROCCO, B. The Feminine in the "Reporter Book": An Epistemological View on Gender and Journalistic Practices. Brazilian Journalism Research, v. 14, n. 1, p. $30-53$, abr./2018.

EMERY, M.; EMERY, E.; ROBERTS, N. L. The press and America: an interpretive history of the mass media. 9. ed. New York: Pearson, 1999.

FARO, J. S. Revista Realidade 1966-1968: tempo de reportagem na imprensa brasileira. Canoas, Porto Alegre: Ulbra/Age, 1999.

GAPY, L. Ponto e Vínculo: jornalismo literário e reportagens seriadas. [s.l.]: Universidade de Sorocaba, 2018.

HARTSOCK, J. C. A history of American Literary Journalism: the emergence of a modern narrative form. Amherst: University of Massachusetts Press, 2000.

HARTSOCK, J. C. Literary journalism and the aesthetics of experience. Amherst, Boston: University of Massachusetts Press, 2016.

HELLER, A. O cotidiano e a história. 12 ed. Rio de Janeiro: Paz \& Terra, 2008.

KEEBLE, R. L. Jornalismo literário como disciplina, além de Tom Wolfe. Brazilian Journalism Research, v. 14, n. 3, p. 894-915, 2018a.

KEEBLE, R. L. Literary Journalism as a Discipline: Tom Wolfe and Beyond. Brazilian Journalism Research, v. 14, n. 3, p. 862-881, 28 dez. 2018 b.

KEEBLE, R.; WHEELER, S. The journalistic imagination: literary journalists from Defoe to Capote and Carter. London; New York: Routledge, 2007. 
KRAMER, M. Invasive procedures: a year in the world of two surgeons. New York: Harper \& Row, 1983 .

KRAMER, M. Three farms: making milk, meat, and money from the American soil. New York: David R Godine Pub, 1986.

KRAMER, M. Breakable Rules for Literary Journalists. In: SIMS, N.; KRAMER, M. (Eds.). Literary journalism: a new collection of the best American nonfiction. New York: Ballantine Books, 1995a. p. 21-34.

KRAMER, M. Travels with a hungry bear: a journey to the Russian heartland. New York: Houghton Mifflin Harcourt, 1995b.

LEWIS, M.; HANC, J. Experiências de educadores no ensino de jornalismo literário: insights obtidos a partir de cinco anos de pesquisas com questionários na internet. Brazilian Journalism Research, v. 14, n. 3, p. 772-805, 2018.

LIMA, E. P. Páginas ampliadas: o livro-reportagem como extensão do jornalismo e da literatura. 1. ed. Campinas, SP: Unicamp, 1993.

LIMA, E. P. Páginas ampliadas: o livro-reportagem como extensão do jornalismo e da literatura. 4. ed. São Paulo: Manole, 2009.

LIMA, E. P. Memória do Futuro: Jornalismo Literário Avançado no século XXI. Revista Brasileira de Inovação Científica em Comunicação, v. 5, n. 2, p. 68-78, 2013.

LIMA, E. P. O jornalismo literário e a academia no Brasil: fragmentos de uma história. Famecos, v. 23, n. 1, p. 1-19, 2016.

LIMA, E. P.; MARTINEZ, M. Eliane Brum: new star in Brazil's Literary Journalism firmament. In: KEEBLE, R. L.; TULOCH, J. (Eds.). Global Literary Journalism: exploring the journalistic imagination. New York: Peter Lang, 2014. p. 171-181.

LONGHI, R. R.; WINQUES, K. The place of longform in online journalism: quality versus quantity and a few considerations regarding consumption. Brazilian Journalism Research, v. 11, n. 1, p. 104-121, 2015.

MARTINEZ, M. Jornalismo literário: um gênero em expansão. Intercom: Revista Brasileira de Ciências da Comunicação, v. 32, n. 2, p. 199-215, 2009 a.

MARTINEZ, M. Jornalismo Literário: a realidade de forma autoral e humanizada. Estudos em Jornalismo e Mídia, v. 6, n. 1, p. 71-83, 2009 b.

MARTINEZ, M. O bom ouvinte: José Hamilton Ribeiro na perspectiva do Jornalismo Literário e da Cultura do Ouvir. Líbero, v. 13, n. 25, p. 121-130, 2010.

MARTINEZ, M. O jornalista-autor em ambientes digitais: a produção da jornalista Eliane Brum para o portal da Revista Época. Comunicação Midiática, v. 9, n. 1, p. 56-77, 2014.

MARTINEZ, M. Jornalismo literário: tradição e inovação. Florianópolis: Insular, 2016a.

MARTINEZ, M. Reflexões sobre Jornalismo e História Oral: um campo com mais convergências do que dissonâncias. Revista Observatório, v. 2, n. 1, p. 75, 1 maio 2016b. 
MARTINEZ, M. Jornalismo Literário: revisão conceitual, história e novas perspectivas.

Intercom: Revista Brasileira de Ciências da Comunicação, v. 40, n. 3, p. 21-36, dez. 2017.

MCGINNISS, J. Doctors, operating. The New York Times, p. 12, 1983.

MEIHY, J. C. S. B.; RIBEIRO, S. L. S. Guia prático de história oral. São Paulo: Contexto, 2011.

MELO, J. M. DE. A opinião no jornalismo brasileiro. 2. ed. Petrópolis, RJ: Vozes, 1994.

MELO, J. M. DE; ASSIS, F. DE. Gêneros jornalísticos no Brasil. São Bernardo do Campo: Umesp, 2010.

MITCHELL, J. O segredo de Joe Gould. São Paulo: Companhia das Letras, 2003.

PASSOS, M. Y.; ORLANDINI, R. A. Um modelo dissonante: caracterização e gêneros do jornalismo literário. Revista Contracampo, n. 18, 19 jun. 2008.

PAULY, J. J. Literary journalism and the drama of civic life. Literary Journalism Studies, v. 3, n. 2, p. 73-82, 2011.

PENA, F. Jornalismo literário. São Paulo: Contexto, 2006.

PERAZZO, P. F. Narrativas Orais de Histórias de Vida. Comunicação \& Inovação, v. 16, n. 30, p. 121-131, jan./abr. 2015.

PERUZZO, C. M. K. Apontamentos para epistemologia e métodos na pesquisa em Comunicação no Brasil. Comunicação e Sociedade, v. 33, p. 25-40, 2018.

RIO, J. DO. As religiões do rio. São Paulo: Nova Aguilar, 1976.

RIO, J. DO. Religions in Rio/As Religiões no Rio (Bilingual Edition). Hanover, Conn: New London Librarium, 2015.

RIO, J. DO. Vertiginous life. Hanover, Conn: New London Librarium, 2017.

ROSS, L. Filme. São Paulo: Companhia das Letras, 2005.

SIMÃO, M. B. R. Jornalismo Literário como género: evolução, implicações e características. [s.l.]: Universidade da Beira Interior, 2018.

SIMS, N. Literary Journalists. New York: Ballantine Books, 1984.

SIMS, N. The Problem and the promise of Literary Journalism Studies. Literary Journalism Studies, v. 1, n. 1, p. 7-16, 2009.

SODRÉ, M. A narração do fato: notas para uma teoria do acontecimento. Petrópolis, RJ: Vozes, 2009.

THOMPSON, P. A voz do passado: história oral. 3. ed. Rio de Janeiro: Paz e Terra, 2002. VILAS-BOAS, S. Perfis: o mundo dos outros. 3. ed. Barueri, SP: Manole, 2014. 
WILDE, M. Three Farms: making milk, meat, and money from the American soil. Mark Kramer. Isis, v. 79, n. 3, p. 298, 1988.

WOLFE, T. Radical chique e o novo jornalismo. São Paulo: Companhia das Letras, 2005 .

WOLFE, T.; JOHNSON, E. W. The new journalism. New York: Harper \& Row, 1973.

ZIELINSKI, S. Arqueologia da mídia: em busca do tempo remoto das técnicas do ver e do ouvir. São Paulo: Annablume, 2006.

Este é um ARTIGO publicado em acesso aberto (Open Access) sob a licença Creative Commons Attribution, que permite uso, distribuição e reprodução em qualquer meio, sem restrições, desde que o trabalho original seja corretamente citado. 